\title{
THE WANGANUI/WHANGANUI DEBATE: A LINGUIST'S VIEW OF CORRECTNESS
}

\author{
Winifred Bauer*
}

\begin{abstract}
A decision was taken in 2009 by the Minister of Land Information that the official spelling of the city formerly spelled Wanganui should henceforth be Whanganui, although a period of grace was given for the change-over. Nonetheless, there is still a good deal of opposition to the change from residents, particularly expressed on many occasions by the outspoken mayor at the time, Michael Laws. This article was originally delivered as a seminar during Māori Language Week 2009, before the decision was taken. It seeks to explore the complex issues that underlie such a decision, and thus to shed light on why the issue is still so controversial. With the success of the case against Wanganui, it is clear that this will not be the last instance where a Māori community seeks legal overthrow of the spelling of a name: already the case of Rimutaka versus Remutaka is being debated.
\end{abstract}

\section{INTRODUCTION}

Spelling is usually decided by convention and not by law. The conventions for the spelling of words other than proper names are normally recorded in dictionaries, which then become the arbiters of correct spelling. Dictionaries will record alternative spellings where more than one is regarded as acceptable in the community. Spelling conventions can change over time, although widespread spelling reform often raises intractable problems. Some proper names may also be recorded in dictionaries, but by and large they are not. When there is dispute over the spelling of a proper name, we cannot, therefore, turn to a dictionary for arbitration. Indeed, with personal names, while some spellings may be seen as more usual than others, any parent can spell a child's name in any way they see fit, and that is then the correct spelling of that child's name. For instance, the name Sean, of Irish origin, has also been spelt Shawn or Shaughan, but if someone chose the spelling Shorn or Shorne for a child, that would also be correct for that child.

* He Pūkenga Āwhina/Teaching Fellow, Te Kawa a Māui, Victoria University of Wellington. 
When it comes to place names in New Zealand, the New Zealand Geographic Board has jurisdiction over names and their spelling. This is a statutory body operating under the New Zealand Geographic Board (Ngā Pou Taunaha o Aotearoa) Act 2008 and reporting to the Minister for Land Information. Under ss $10-12$ of this Act, the New Zealand Geographic Board has jurisdiction (amongst other things) to assign official names to places, and to alter a place name by correcting its spelling. Accordingly, the New Zealand Geographic Board was the body asked to consider correcting the established, and conventional spelling of Wanganui to Whanganui.

If a spelling requires correction, there is an implication that the conventional spelling is wrong. But since right and wrong spelling is a matter of convention, of what is accepted as the norm by the community, it is unclear on what grounds a conventional spelling could be deemed to be wrong. The only obvious grounds for such a claim would be that there had been a clearly stated intention in the original naming process to name the place after some specified entity, and that this intention was obscured by a mis-spelling of the name of that entity. Thus, if it was agreed that a particular mountain peak was to be named after Sir Edmund Hillary, but it was called Mt Hilary, there would be a case for considering this an incorrect spelling.

The issue in relation to Wanganui/Whanganui is rather different. It arises because there are two languages involved, and thus two sets of spelling conventions. In this case the two conventions are in conflict. This article sets out the linguistic issues, and endeavours to separate those that are purely linguistic from the other issues that are involved, for example which language should take precedence in a case of this kind, and how that is to be decided?

There are three linguistic issues involved in the debate over the spelling of Wanganui/Whanganui.

1. How is the initial consonant in this word pronounced? That question can only be addressed by considering what people actually say, and what they said at the time the conventional spelling was determined.

2. How should that pronunciation be recorded in the spelling? That can only be addressed by considering the relationship between pronunciation and spelling in the language(s) concerned.

3. What language does this word belong to? That determines the appropriate spelling conventions, as well as the pronunciation. We can only answer the first two questions if we consider this third one. This is a question that was largely ignored in the public debate on the Wanganui/Whanganui case, though I believe it is crucial.

In addition to these linguistic issues, the debate about Wanganui/Whanganui has other dimensions that are not linguistic, but political and economic. It is not my intention to discuss these in detail, though I will raise them. But I hope, that it will become clear to what extent this is a 
linguistic question, and to what extent it is a political one by clarifying the linguistic issues. This raises important questions about the appropriate means of determining what is a correct spelling in the case of place-names.

\section{SOME LINGUISTIC CONVENTIONS}

A discussion of the issues necessarily involves a discussion of both spelling and pronunciation. A small amount of technical notation is thus unavoidable in this paper, although it will be kept to a bare minimum.

In accordance with usual linguistic practice, angle brackets are used to enclose spellings $<\ldots>$ while forward slashes enclose phonemic transcriptions /.../. Phonemic transcriptions use a special set of characters known as the International Phonetic Alphabet (IPA) to record pronunciation. In the IPA system each character always represents only one sound. The letter $\langle\mathrm{c}\rangle$ in English, which is pronounced in three different ways in the highlighted places in the words electric, electricity and electrician, is transcribed $/ \mathrm{k} /$ in the first case, $/ \mathrm{s} /$ in the second and $/ \mathrm{J} /$ in the third. The IPA uses roman characters where possible, and special characters where necessary.

I will make use of one further convention. The asterisk is used by linguists to mark sentences that are ungrammatical, pronunciations that are not possible, and forms which are deduced (but not known with total certainty) to belong to pre-documentation states of a language. Thus using this notation, a linguist might write "<finger> is not pronounced */fıjə/, but /fıngə/". The asterisk precedes the wrong or impossible pronunciation; note that $/ \mathrm{y} /$ is the IPA symbol for the (single) consonant sound at the end of English ring.

\section{NAMING PLACES}

Māori, like people the world over, name geographical features descriptively, or according to some event that took or takes place there. In New Zealand, there are Māori place names like Maunga-nui, where "maunga" is "mountain" and "nui" is "big", because the salient feature of the peninsula with that name is the large prominence at the end. Similarly, Kai-kōura is so called because of an activity associated with the place: "kai" is "eat", and "kōura" is "crayfish". (The conventional spelling of these Māori names does not hyphenate the separate elements, although some scholars ${ }^{1}$ have advocated this practice. I have done it here for clarity.) Parallel examples are readily found in English. Thus in Grinsted, the "grin" element comes from an early form of "green" and "sted" means "place" (today spelled "stead"). "Grinsted" is thus "green place". Derby comes from the name given to it by the Viking settlers: Deor by, where "deor" means "deer" and "by"

1 See Bruce Biggs "Introduction" in Pei te Hurinui Jones and Bruce Biggs Ngā iwi o Tainui: The traditional history of the Tainui people/Ngā koorero tuku iho a nga tupuna (Auckland University Press, Auckland, 1995) 1 at 2. 
means "village": a village where deer are found or hunted or plentiful. ${ }^{2}$ Notice that the spelling of Grinsted has not been updated to reflect the change in the conventional spelling of the meaningful elements (it is not Greenstead). The spelling of Derby has changed but it has not changed to the modern conventional spelling of the initial element (which would be Deerby). Spellings are a matter of convention, and not necessarily subject to logic or consistency, and, since the advent of printing, do not generally change even when the pronunciation does.

The name Wanganui/Whanganui is understood by Māori people to mean "big bay". The city or river or district of the current dispute is not the only place so named in New Zealand. One of the names for the Wellington area is "Te Whanga-nui-a-Tara": "the big bay of Tara (and notice that the word for "bay", "whanga", here is spelled with <wh>). The entry in the Williams Dictionary ${ }^{3}$ under "whanga" includes the senses "bay, bight, nook; stretch of water". The entry for "nui" includes "large" as the first sense.

The Williams Dictionary does not contain an entry for wanga, nor anything it could be derived from. The closest entries alphabetically are wani followed by wao. (In this dictionary, <ng > is alphabetised as a separate letter, distinct from, and following $\langle\mathrm{n}\rangle$, so that tānumi immediately precedes tānga). Whanga is thus a traditional Māori word; wanga is not to be found in any dictionary of Māori. Furthermore, the sense of whanga is clearly understood as an element in the meaning of Wanganui/Whanganui.

\section{THE PRONUNCIATION OF 〈WH $\rangle$}

At the time when Europeans came to New Zealand, the initial consonant of the Māori word for bay had very variable pronunciations. ${ }^{4}$ Some of the variation in pronunciation was tribally based, but there is now good evidence that individual speakers also had a significant variety of pronunciations of this consonant at one time. The most thorough evidence of that comes from Maclagan and King. ${ }^{5}$ In this paper, Maclagan and King present an analysis of the variation in the pronunciation of $\langle w h\rangle$ in the speech of a native speaker of Māori born in the 1880s, and recorded in the 1940s. That speaker used five different pronunciations of <wh> in the course of an hour's recording. None of those variants was /w/.

2 Both examples from Tim Lambert "The Origins of Some English Place Names" A World History Encyclopedia <www.localhistories.org>.

3 HW Williams (ed) A Dictionary of the Maori Language (7th ed, Government Printer, Wellington, 1971).

4 See HW Williams, WL Williams, and WT Ngata First Lessons in Maori (13th ed, Whitcombe and Tombs Ltd, Christchurch, 1965) at 10; Bruce Biggs "The Structure of New Zealand Maaori" (1961) 3 Anthropological Linguistics 1 at 9.

5 Margaret Maclagan and Jeanette King "The pronunciation of $w h$ in Māori - a case study from the late nineteenth century" (2002) Te Reo 45. 
Although /f/ is the most common pronunciation of <wh> today, that was not always the case. Smyth, ${ }^{6}$ for example, calls it "incorrect". Even today, /f/ is not the most common pronunciation in the far north of New Zealand, where /hw/ is at least as likely.

Professor Samuel Lee from Cambridge University devised the original spelling system for Māori, by working with Māori consultants sent to England for this purpose. ${ }^{7}$ Lee's system was first published in $1820 .{ }^{8}$ His alphabet did not include $\langle w h\rangle$. It did include $\langle f\rangle$ but commented that $\langle f\rangle$ was "used in Foreign words". 9 That comment makes it clear that $\langle\mathrm{f}\rangle$ was not included as the spelling for the sound at the beginning of whanga, for example. There is evidence in Lee's work that he did not hear the distinction between the sounds today spelled $\langle w\rangle$ and $\langle w h\rangle$. His list of numbers includes <witu> ("7") and <waru> ("8"), ${ }^{10}$ where today we write <whitu> and <waru>, and his vocabulary includes <ware> ("house"). ${ }^{11}$ The most likely explanation is that the pronunciation of whitu and whare that he heard from his Māori consultants was a voiceless (for example, whispered) $\mathrm{w}, / \mathrm{M} /$, which is the main pronunciation recorded in the Williams description. ${ }^{12}$ In other words, the Māori speakers that Lee heard were making different sounds at the beginning of <whitu> and <waru>, (sounds as different as English /f/ and /v/), but Lee's ears did not pick up this distinction. $\mathrm{He}$ had, after all, only three months in which to devise a spelling system and produce a grammar; a modern field linguist working on an undescribed language would spend at least 10 months immersed in the field.

Over the years that followed, a number of refinements were made to Lee's proposal for the Māori alphabet by the missionaries in New Zealand who were working on Bible translation. In particular, they removed all the characters for non-Māori sounds which Lee had included, and introduced a greater consistency both by removing some inappropriate distinctions included by Lee, and by making some distinctions which Lee had missed. By the time that the New Testament was translated into Māori, <wh> began to appear in written Māori texts, and it was fully established by 1852, from which we can deduce that the Māori who worked with the missionaries on these

6 Patrick Smyth Maori Pronunciation and the Evolution of Written Maori (Whitcombe and Tombs, Christchurch, 1946) at 8.

7 Ibid, at 23-25.

8 Samuel Lee and Thomas Kendall A Grammar and Vocabulary of the Language of New Zealand (Church Missionary Society, London, 1820). The resource is available through the NZ Electronic Text Centre <www.nzetc.org>.

9 Ibid, at 1; Smyth, above n 6, at 27-28.

10 Lee and Kendall, above n 8, at 17.

11 Ibid, at 6; Smyth, above n 6, at 28-29.

12 Williams, Williams and Ngata, above n 4, at 10. 
translations were aware of this deficiency in Lee's system, and it was soon remedied. Again, from the fact that the spelling chosen was $\langle w h\rangle$, not $\langle\mathrm{f}\rangle$, we can deduce that what the missionaries heard at that time was a sound more akin to the sound at the beginning of English which (if distinguished from witch), and not an $\langle\mathrm{f}\rangle$.

Variability in the pronunciation of $\langle w h\rangle$ has continued to be noted by more recent scholars. Biggs ${ }^{13}$ notes a northern variant as "a voiceless and strongly aspirated /w/". Aspiration is the $/ \mathrm{h} /$ sound, so this variant combined the qualities of whispered $w$ and $/ \mathrm{h} /$. In his discussion of the pronunciation in modern Polynesian languages of the *f sound of Proto-Eastern Polynesian (the ancestor language of the branch of Polynesian to which Māori belongs), Biggs notes ${ }^{14}$ that for North Auckland Māori, it is /hw/, but it is glottal stop in Taranaki-Wanganui, and / $\Phi /$ (an f-like sound made by blowing air between the pursed lips, like blowing out a candle) for Māori generally.

From the point of view of the Wanganui/Whanganui controversy, what matters most is that, in western and northern areas of the North Island, the /hw/ pronunciation was normal at the time when Māori was still widespread as a first language. However, in Taranaki, and up the Whanganui River as far as Taumarunui, the $/ \mathrm{h} /$ sound of Māori was replaced at some point before the arrival of the Europeans by a glottal stop (IPA symbol/R/). So in that area, the normal pronunciation at that time (still heard from local dialect speakers) was / ?aere/ rather than /haere/, / Paka/ rather than /haka/. As a result, the glottal stop also replaced the $/ \mathrm{h} /$ at the beginning of <wh> words (with the $/ \mathrm{hw} /$ pronunciation), giving / $\mathrm{P} /{ }^{15}$

English speakers are familiar with the use of the glottal stop in some dialects of English, notably Cockney, where it replaces /t/ and /d/, as in "a bit of butter" pronounced by Cockneys as (roughly) /o bi? a b ? $_{\Lambda} /$. But the glottal stop is not confined to such dialects of English. All English speakers regularly make glottal stops in "uh, uh" (in transcription, $/ 2 \wedge$ ? $2 /$ ). A glottal stop can also be used to separate consecutive vowels, and so might be used to separate the final vowel of law from the initial vowel of and in the phrase "law and order", although there is also the possibility of using a linking /w/ or even /r/: /lo Pən odə/ or /lo wən ədə/ or /lo rən odə/. A glottal stop can occur at the beginning of a word if the word is emphasised, so to emphasise awfully in "I'm awfully sorry" the speaker may put a glottal stop before awfully. However, English speakers do not pay attention to these glottal stops, because they do not change the sense of what is said, and so English speakers are not usually aware of using glottal stops at all.

13 Biggs, above $\mathrm{n} 4$, at 9.

14 Bruce Biggs "The Languages of Polynesia" in TA Sebeok (ed) Current Trends in Linguistics; Linguistics in Oceania (Mouton, The Hague, 1971) vol 8 at 481.

15 Ibid; Ray Harlow Maori: a Linguistic Introduction (Cambridge University Press, Cambridge, 2007) at 45. 


\section{MATCHING THE PRONUNCIATION WITH THE SPELLING}

The first job of any alphabetic spelling system is to provide a written representation of the pronunciation. However, no spelling system records pronunciation with complete accuracy, and so all spelling systems are only a rough guide to the pronunciation. They concentrate on recording the important elements of the pronunciation. If an English speaker says bat and bad, the vowels are very different in length, but we do not record that aspect of the pronunciation in our spelling. The /1/ sounds at the beginning and end of lull are not identical, but we do not record that in our spelling. The /k/ sounds in Māori "kā" ("burn") and "kī" ("say") are different, but the spelling does not record that. All these unrecorded differences are predictable from the environment of the recorded sounds.

There are two possible explanations for why the English settlers spelled Wanganui with a $\langle w\rangle$. I do not think that it is possible to determine which was the actual explanation, and nor does it make much difference to the problem under consideration. The first possibility is that they first wrote the name down using Lee's original system before it had been refined to include the $\langle w\rangle \mid\langle w h\rangle$ distinction. Lee's system at that point did not give them a way to distinguish between $\langle$ Wanganui $>$ and <Whanganui $>$.

The second, and I believe more plausible, explanation is that they wrote what they thought they heard from the local Māori speakers. If an English speaker listens to the Taranaki-Whanganui tribal pronunciation of <Wanganui $>$ with ears trained by English, although there will be a glottal stop (the name begins / $\mathrm{r}$ /) which a machine would register, English speakers will notice only the /w/. They have learned through English to ignore glottal stops at the beginning of words, because they are never important in English in terms of working out what word it is that has been said. In that position, a glottal stop is most likely to signal emphasis. Thus when English people wrote down the local Māori pronunciation of Whanganui, they heard (and therefore said, and wrote) only the /w/, and ignored the glottal stop. They were writing it in English, in accordance with English spelling conventions, so they wrote $\langle w\rangle$, because that is the standard spelling in English of the sound /w/.

If the settlers had listened to speakers from other parts of the country, who would have said not $/ \mathrm{Rw} /$, but one of the other varieties, such as $/ \mathrm{hw} /$ or $/ \phi /$ or $/ \mathrm{f} /$, they would almost certainly have written something else. The spelling <Wanganui> is thus a spelling using English spelling conventions that English ears heard from local Māori speakers.

The conventional spelling system for Māori did not provide speakers of the TaranakiWhanganui dialect with an accurate way of writing their actual pronunciation, / ?w/, in Māori, even when it had been refined by the addition of $\langle w h\rangle$ by the Bible Translation Committee. ${ }^{16}$ All Māori speakers use the conventional $<w h>$ spelling for words like whitu, whare and whanga, regardless of

16 Smyth, above n 6, at 39. 
whether they say /hw/ or /f/ or / $\mathrm{w}$ / (or one of the other variants). By this convention, TaranakiWhanganui speakers, like speakers of all other dialects of Māori, would write their pronunciation $<$ Whanganui> using the conventions established for Māori spelling. Indeed, it is only very recently that other Polynesian languages have begun to record their glottal stops even where they are contrastive consonants. This is usually done today by means of an apostrophe. Thus it is traditional Samoan orthography to write "ia" ("fish") and "waa" ("canoe"), although Samoans say /i?a/ and /wa?a/; today Samoans sometimes record the glottal stop in the orthography by writing these as $<i ' a>$ and <wa'a> with the apostrophe. ${ }^{17}$

We have thus established that <Wanganui> was an appropriate English spelling for what the English settlers perceived the local tribes to call this place, but also that <Whanganui> is the appropriate Māori spelling for all Māori tribes, regardless of their pronunciation of the initial consonant.

\section{SPELLING RECORDS MORE THAN PRONUNCIATION}

Spelling systems do another job as well as recording pronunciation. They spell elements of words that mean the same thing in the same way, as far as possible. That expectation often comes into direct conflict with the requirement that spellings should record pronunciation reasonably accurately. There is a reason why, in English, the conventional spelling has electric and electricity and electrician with a $\langle\mathrm{c}\rangle$ in the places highlighted, even though, as noted above, the first bold $\langle\mathrm{c}\rangle$ is pronounced as a $/ \mathrm{k} /$, the second as an $/ \mathrm{s} /$, and the third as $/ \mathrm{J} /$ like $<\mathrm{sh}>$. If the spelling were to reflect the pronunciation, it would hide the fact that the first element in each of these words is the same element in terms of sense. That would not be nearly as obvious if these words were spelt electric, electricity and electrishin. Indeed, spellings like those would suggest (wrongly) that the first element was electri. Often if these two expectations are in conflict, communities choose to prioritise the principle of spelling the same part the same way, over the principle of reflecting the pronunciation.

That happens in Māori too. There is a problem with the spelling of the word formed by adding the prefix whaka- to a word like āhua ("form, appearance"). This process leads to the sequence of a short $\langle\mathrm{a}\rangle$ (here transcribed $/ \Lambda /$ ) followed directly by a long $<\overline{\mathrm{a}}>$ (here transcribed /a:/). When Māori

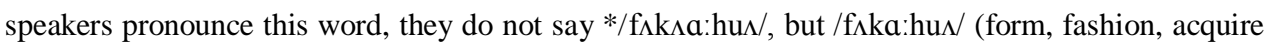
form; draw and photograph for example). If the spelling reflects the pronunciation, and uses the macron spelling for a long a as in <whakāhua >, it hides the fact that the prefix is whaka-, not whak-. If the long vowel is spelled with a sequence of two short ones, as advocated by Bruce Biggs, it hides the fact that the base is āhua: <whakaahua>. Te Taura Whiri i te Reo Māori, a statutory body with

17 Ulrike Mosel and Even Hovdhaugen Samoan Reference Grammar (Scandinavian University Press, Oslo, 1992) at $17-18$. 
the responsibility for decisions concerning the Māori language, in fact decreed ${ }^{18}$ that it should be spelled whakaahua, but even they themselves do not always follow their edict, and most of the general public in my experience write whakaāhua. In other words, people choose the spelling which preserves the identity of the elements, rather than the one which reflects the pronunciation. It is people who decide on the conventional spelling; it is determined by common usage.

\section{WANGANUI/WHANGANUI: CHOOSING THE CORRECT SPELLING}

Applying these two principles to the Māori spelling of the Wanganui/Whanganui case, it is clear that the spelling $<$ Wanganui $>$ inaccurately reflects the Māori pronunciation. (Using $<\mathrm{W}>$ rather than $<$ wh $>$ in Māori is like spelling English cat as $<$ dat $>$ or $<$ bat $>$ ! At the same time, it fails to represent the first meaningful element appropriately. The spelling <Whanganui $>$ accurately reflects the meaningful elements, and it conventionally reflects the pronunciation of all dialects, since the <wh> is conventionally used in the Māori spelling system to represent whatever variant of this sound is actually used. It is appropriate to have just one representation of all this variety in the pronunciation of $\langle w h\rangle$ for the same reason that in English we do not spell the vowels of bat and bad differently, or the /l/'s of lull differently: changing between these variant sounds does not cause the word to change in sense.

When it comes to the English spelling of Wanganui/Whanganui, the principle of maintaining meaningful elements does not apply, since this name does not have English elements. Only the pronunciation is involved, and I have already demonstrated that <Wanganui > was a reasonable way to spell in English what the local Māori dialect speakers said.

Thus linguistically, the case in relation to the spelling of Wanganui/Whanganui is clear. The $<$ wh $>$ spelling is unquestionably the only one that is justified in Māori: the appropriate Māori spelling is <Whanganui>. The spelling <Wanganui> is justified in English as a representation of what the pronunciation of the tribes of that area sounded like through the filter of English trained ears.

Appealing to the intention of the namers (as in the hypothetical Mt Hillary case outlined above) does not resolve this issue. It is clear that the Māori namers intended to call it "big bay", and this confirms the correctness of $<$ Whanganui $>$ in Māori. The intention of the English settlers was most probably to call the place by the closest English equivalent of the name used by the local tribes, which they heard as beginning with /w/, and so the spelling <Wanganui> must be deemed to have fulfilled their intention.

18 Te Taura Whiri i te Reo Māori He Muka (Te Taura Whiri i te Reo Māori, Wellington, 1992) at 7. 
It is thus clear that to determine the correct spelling of this name, the Geographic Board needed to consider not just how it should be spelled, but which language it is being spelled in.

To think about that issue, it is necessary to ask the question of whether this name is exclusively a Māori name or whether it is an English name as well. I will address this issue by considering a parallel question the other way round: is "tēpu" ("table") a Māori word?

The word tēpu exists; it is used in New Zealand, so it must belong to some language spoken in New Zealand. It cannot belong to English, because no English speaker ever uses that word when speaking English (except possibly to cite it as a Māori word). The fact that when it is used it is typically surrounded by other words which are exclusively Māori would suggest that it is indeed a Māori word. Consistency then leads to the conclusion that, in a parallel way, Wanganui is an English word. Just as tēpu represents how Māori people pronounce the originally English word table when they are speaking Māori, "Wanganui" represents how most English speakers pronounce the originally Māori word Whanganui when they are speaking English.

Māori people feel that it is perfectly appropriate to spell tēpu in the way that they pronounce it when they are writing Māori. There is a parallel case for saying that English speakers have the same right to spell Wanganui as they pronounce it when they are writing English.

That means that, linguistically, the solution to the dilemma is easy: this place is called

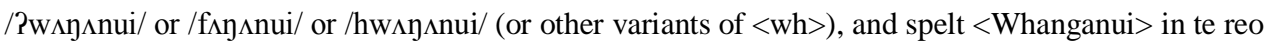
Māori, but pronounced /wpy(g)ən(j)ui/ and spelled <Wanganui $>$ in English. (The transcription of the English pronunciation contains two variants in brackets: the /g/ is included because some English speakers pronounce the $\langle\mathrm{ng}\rangle$ as in finger, rather than as in wringer; the $/ \mathrm{j} /$ is included because some speakers pronounce the $<$ nu $>$ sequence as in British English new (with a $/ \mathrm{j} /$, the sound that starts the word yellow, after the $/ \mathrm{n} /$ ) and others pronounce it as in United States English new, with no $/ \mathrm{j} /$.) In other words, there is no dilemma; there are two spellings, each appropriate in one of the two languages concerned.

However, this does not resolve the issue in practical terms, because things like maps, road signs and notices all have to serve both languages. While it would be feasible to label it Whanganui/Wanganui, or W(h)anganui I think everyone recognises that this is both cumbersome and undesirable. For practical purposes, it is necessary to agree on a common spelling that will serve both languages. The Geographic Board was then being asked to choose between two correct spellings, rather than to replace an incorrect spelling with a correct one.

At this point, the issues cease to be purely linguistic, and also probably fall outside the jurisdiction of the New Zealand Geographic Board as specified in the Act that governs it. 


\section{ISSUES IN CHOOSING BETWEEN TWO COMPETING CORRECT SPELLINGS}

The public debate around this issue was very frequently made to sound as if the issues were purely linguistic. However, the majority of these supposed linguistic issues on closer examination turn out to be political in nature. This section examines a number of arguments that might be put forward to resolve the issue.

It might be argued that the common spelling should be the Māori one, because that is the original language, and the English spelling represents an adaptation of that into English. While this might sound like a linguistic reason, it is not: linguistics does not provide any reason to prioritise the spelling of the donor language over the spelling of the receiving language; if it did, têpu in Māori would have to be spelt table, and weta in English would have to be spelt wētā. Prioritising one language over the other is a political decision.

It might be argued that it is the Māori spelling that preserves the identity of meaningful elements. Again, that might sound like a linguistic argument, but it is not: linguistics does not require us to prefer a spelling of that kind. We spell truth and width in English without an $\langle\mathrm{e}\rangle$, although that hides the fact that these words derive respectively from true +- th and wide + -th.

It might be argued that, in most other cases where we use place names derived from Māori, we use the Māori spelling, including those with the element whanga, so for consistency, we should use the Māori spelling here, too. In New Zealand, there are places called Whanga-roa, Whanga-paraoa, Whanga-mata, Whanga-ruru, Whanga-rā, Whanga-ehu, Whanga-mumu... amongst many others. That is not solely a linguistic argument, since linguistics does not require us to spell consistently, as the English spelling system amply demonstrates. There are also other place names that were originally Māori but are not conventionally spelled as they would be in Māori. Petone is a case in point: it derives from pito + one, and the spelling $<$ Pitoone $>$ is appropriate in Māori. Decisions about consistency are editorial decisions, not linguistic ones.

It might be argued that while the spelling $<$ Wanganui $>$ is clearly incorrect in Māori, neither spelling is clearly incorrect in English, since the English spelling is determined by the Māori pronunciation, and there are pronunciations of the name in Māori which justify either English spelling. However, this ignores the fact that spelling is conventional, and the English convention is $<$ Wanganui>; so it can be argued that, conventionally, <Whanganui> is incorrect in English. Again, the linguistic arguments do not point to a solution.

It might be argued that using the Māori spelling enhances the mana of te reo Māori, so English speakers should be politically correct, and cede their right to spell it as they pronounce it as a gesture of goodwill. That is clearly another political decision, not a linguistic one. 
On the other hand, it might be argued that the common spelling should be the English one, because English is the majority language, and that in a democracy, the majority rules. That is also clearly a political argument.

There are significant economic issues at stake, too: changing the spelling involves a great deal of time and money.

There were no principles available to the Geographic Board to help them to weigh such disparate arguments against each other. They rightly decided that, since most of the arguments are political, the decision should be political, and handed the decision to the Minister of Land Information.

\section{HOW IS WANGANUI/WHANGANUI TO BE PRONOUNCED?}

There is now discussion in the media about what is the correct way to pronounce the name of this city following the ministerial decision about its spelling. In some ways that is odd, since the spelling is supposed to reflect the pronunciation, and not the reverse.

There are essentially two options: to use the local Māori dialect pronunciation, or to use the semi-standardised pronunciation associated with Māori $<w h>$. The latter today is $/ \mathrm{f} /:$ that is what is used by the media in words like whānau and whare. There are two options in terms of dialect. One is the very localised / $\mathrm{Pw} /$, which will sound to most listeners as if the $\langle\mathrm{h}\rangle$ is being ignored, although hopefully not to the older local Māori people, at least. The other is to use the /hw/ that for some English speakers distinguishes which from witch, a pronunciation which approximates the more widespread dialect pronunciation of the north and west of the North Island.

Again, the choice is a matter of politics, but it has ramifications of a significant kind. If broadcasters choose to adopt either of the local dialect pronunciations, then speakers of other Māori dialects may expect them to be consistent. Are broadcasters then going to pronounce the South Island place name Rangiora with/k/ instead of / $\mathrm{y} /$, to reflect Ngai/Kai Tahu dialect?

In pronunciation, as in spelling, the issues are not issues of law that can be decided by a body with legal jurisdiction. Whereas spelling conventions can be decreed by politicians, and, at least in public places, policed, pronunciation is much less subject to decree. Politicians can do little more than advise and direct public servants. Broadcasters probably have more influence over conventional pronunciation than any political decree. But ultimately, what is considered correct in language - including pronunciation and spelling - will be decided by consensus in the community of speakers. That consensus may of course be to tolerate variability.

\section{CONCLUSION}

Spelling reform, for whatever reason, is always fraught with difficulties and contradictions, no less in this case than in any other. However, spelling reform is even more complex here, because 
two languages are involved. The Geographic Board was asked to perform a task for which there are no guidelines, linguistic or otherwise. Although the issue was often presented as a matter of determining the correct spelling, it was not. It was a matter of choosing whether the spelling that is appropriate according to the conventions of Māori should have precedence over a spelling that is appropriate according to the conventions in English, and established by conventional use. That is ultimately a political question, and therefore outside legal jurisdiction. It is appropriate, therefore, that the Geographic Board did not decide on the issue, but handed the political decision to a politician. 
